\title{
Coordinated Operation and Control of VSC based Multi-terminal High Voltage dc Transmission Systems
}

\author{
Ali Raza, Xu Dianguo, Senior Member, IEEE, Liu Yuchao, Su Xunwen, Barry Williams ,Carlo \\ Cecati, Fellow, IEEE
}

\begin{abstract}
This paper deals with a multi-terminal voltage source converter (VSC) based high voltage de transmission system (M-HVDC) connecting offshore wind farms to onshore ac grids. Three M-HVDC configurations studied, each with different control strategies. The voltage-current characteristics of VSCs are presented and VSC converter operation with different output powers from offshore wind farms is assessed. A generalized droop control strategy is mainly used to realize autonomous coordination among converters without the need of communication. Operation of the three configurations with respect to their control system is analyzed through PSCAD/EMTDC simulations and experimentation. Results show control performance during wind power change, eventual permanent VSC disconnection, and change in power demand from the ac grid side converter.
\end{abstract}

Index Terms-Configuration, VSC based multi terminal HVDC,offshore wind farms, improved proportional droop control, generalized droop control strategy.

\section{INTRODUCTION}

$\mathrm{O}$ FFSHORE wind farms are situated tens or hundreds of kilometers off shore and integrated into the mainland grid through submarine cables. Studies have established that multi terminal high voltage direct current (M-HVDC) is an appropriate energy transmission system in these situations [1], [2]. Research on multi terminal voltage source converter (VSC) based HVDC transmission systems consist of simulations, modeling [3]-[7], protection [8], [9], control systems [2],[6],[10]-[12] and short circuit dc faults [13], which have received increased attention in recent years. This evolution is because of two reasons: (i) capacity to interconnect several ac grids operating at different voltages even at asymmetric frequencies and (ii) appropriateness of a multi terminal VSC HVDC system (M-VSC-HVDC) to integrate large offshore wind power plants. Reactive power support, black start capability, small filter sizes, and the ability to change the power direction without altering the polarity of the dc link voltage make VSC based HVDC a viable candidate for multi terminal HVDC rather than line commutated converter (LCC) technology.

Manuscript received June 30, 2015; revised September 24, 2015; accepted for publication October 28, 2015. This work was supported in part by the Power Electronics Science and Education Development Program of Delta Environment and Educational Foundation's project DREM2012001 and the National Science Foundation of China under Grants 51237002 and 51107015.

Copyright (c) 2009 IEEE. Personal use of this material is permitted. However, permission to use this material for any other purposes must be obtained from the IEEE by sending a request to pubspermissions@ieee.org.

Ali Raza, Xu Dianguo, Liu Yuchao are with the School of Electrical Engineering and Automation, Harbin Institute of Technology, Harbin, 150001, China (e-mail: i.will.rize@gmail.com; xudiang@hit.edu.cn; li.yuchao@yahoo.com).

$\mathrm{Su}$ Xunwen is with Heilongjiang University of Science and Technology, China (suxunwen@yahoo.com).

Barry W. Williams is with Strathclyde University, UK (Barry.Williams@strath.ac.uk).

Carlo Cecati is with Università degli Studi dell'Aquila, Italy (carlo.cecati@univaq.it).
DC voltage control and active power control are important performance tests for a HVDC system. In dc grids, power sharing among the terminals is governed by the dc network voltage. Thus, one objective of this paper is to maintain the dc link voltage within a defined limit of $\pm 5 \%$ [14], [15] for system stability, rather than selecting a $\pm 10 \%$ tolerance limit as dc link voltage control design [16] [17]. This is not as safe limit as $\pm 5 \%$.

DC voltage droop is frequently employed for dc voltage control in M-VSC-HVDC [7], [18], [19]. It originates from frequency-power droop control of ac system. In this technique, voltage regulating VSCs share real power based on their respective voltage droop coefficients. It shows higher reliability than master slave control [20] and does not generate voltage oscillations like the voltage margin approach. However, droop control has some drawbacks like: (i) full power flow control cannot be performed as real power cannot be fixed at a constant level and (ii) it cannot fix the dc voltage of converters, if needed [6]. In order to overcome these shortcomings, a generalized droop control structure is proposed in [6] to inter-change between dc voltage control modes based on the M-HVDC grid parameters, and is achieved through a dual hierarchical architecture.

The coordinated dc droop characteristic technique proposed and simulated in [7], [10], [12] described modeling, control and simulation of a M-HVDC system. Droop control is designed considering linearized ac and dc system dynamics in [15]. Currently there is no systematic control design procedure or stability analysis for M-VSCHVDC for connecting large offshore wind power plants. This paper scrutinizes the stability and dynamic behavior of multi terminal VSC HVDC transmission systems for offshore wind farm applications. Three M-VSC-HVDC transmission system configurations, with four control schemes are outlined in section II. Section III describes the design procedure for the experimental test bed. The configurations are analyzed and assessed by means of dynamic simulations and experimentally, in section IV, in terms of wind power change, eventual grid side converter loss, and abrupt change in load demand. Finally, conclusions are presented in section $\mathrm{V}$.

\section{CONTROL AND CONNECTIONS OF MULTI TERMINAL VSC HVDC}

Three M-HVDC transmission system configurations are considered that connect offshore wind farms (WF) to mainland ac grids (GS).

\section{II.1: DC voltage droop control on grid side converters}

The system consists of two offshore wind farm VSC

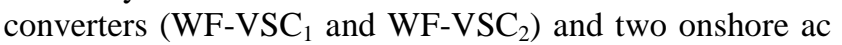
grid side VSC converters (GS-VSC 1 and $\mathrm{GS}_{1}-\mathrm{VSC}_{2}$ ) as shown in Fig. 1. WF-VSC 1 and $\mathrm{WF}_{1} \mathrm{VSC}_{2}$ collect wind power from $\mathrm{WF}_{1}$ and $\mathrm{WF}_{2}$, respectively, and deliver it to the dc network. Then, power is transmitted to onshore ac 


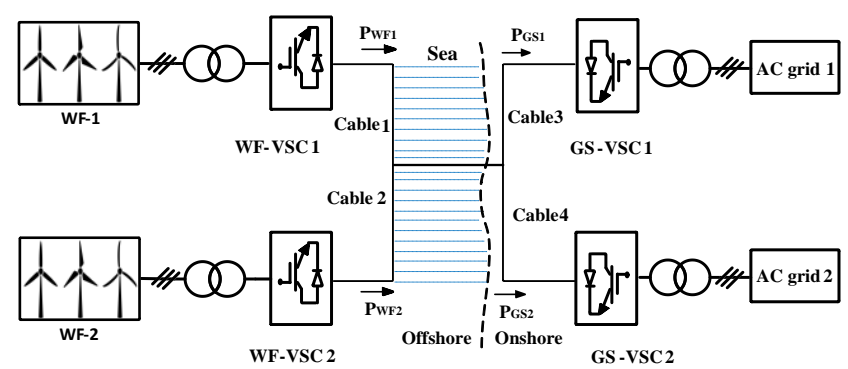

Fig. 1: Integration of two offshore wind farms with two onshore ac grids through submarine HVDC cables.

grids through GS-VSC 1 and GS-VSC 2 . Each converter dc side is connected together through submarine dc cables.

The controller in Fig. 2 is used to maintain the ac voltage of the wind farms at a specific level. A $60 \mathrm{~Hz}$ constant voltage is produced by controlling its magnitude through proportional integral (PI) control which minimizes the error ( $\mathrm{e}=\mathrm{V}_{\mathrm{WF}} *_{-} \mathrm{V}_{\mathrm{WF}}$ ) and is used as a performance index for this controller. The PI controller parameters are in Table I.

Fig. 3 shows the controller used with the grid side converters to regulate the dc voltage and reactive power to the onshore ac grids. The proportional droop controller shown in Fig. 4 is used to coordinate the dc voltage between GS-VSC 1 and GS-VSC 2 , where, $\mathrm{V}_{\mathrm{g}}{ }^{*}$ pu and $\mathrm{P} * \mathrm{pu}$ are the reference dc voltage and active power. $K$ is the slope of droop characteristics and $\mathrm{V}_{\mathrm{g}} \mathrm{pu}$ is the grid side converter dc voltage with zero power. It is advantageous over common droop control as it transfer minimum error to the PI controller through limiters.

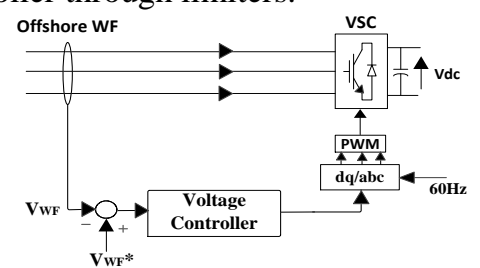

Fig. 2: Controller to establish the constant ac voltage at WF.

Table I: Proportional Integral controller parameters.

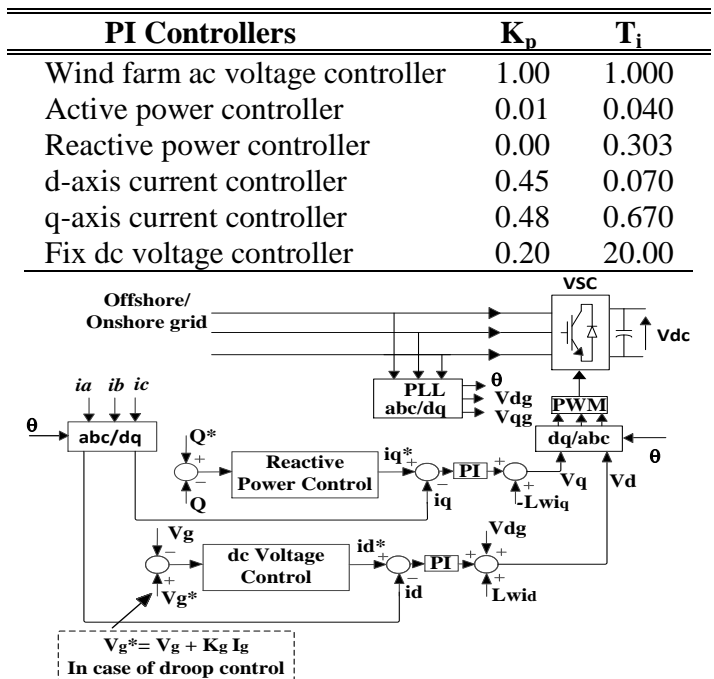

Fig. 3: DC voltage control by using d-q control method.

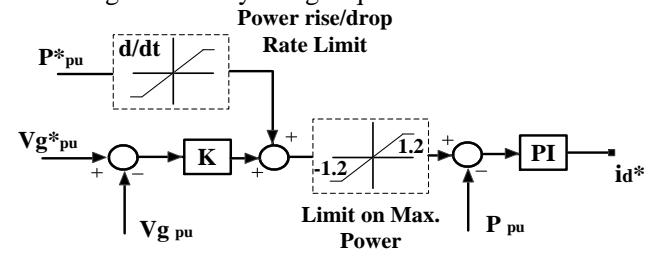

Fig. 4: Improved proportional droop control.

\section{II.1.1: V-I characteristics of configuration 1}

A V-I characteristics of the converters for configuration1 are shown in Fig. 5. The solid curves represent the characteristics of $\mathrm{WF}^{-V_{S C}}$ and $\mathrm{WF}_{1} \mathrm{VSC}_{2}$ with wind powers $\mathrm{P}_{\mathrm{WF} 1}$ and $\mathrm{P}_{\mathrm{WF} 2}$, respectively. The straight lines $\mathrm{LN}$ and $\mathrm{LM}$ depict the droop characteristics of GS-VSC $\mathrm{VAn}_{1}$ and $\mathrm{GS}_{\mathrm{VSC}}$. Assume that all the converters have the same dc voltage level $\mathrm{V}_{\mathrm{WF} 1}=\mathrm{V}_{\mathrm{WF} 2}=\mathrm{V}_{\mathrm{GS} 1}=\mathrm{V}_{\mathrm{GS} 2}$, illustrated in Fig. 5 with the solid horizontal line. The intersections of the horizontal line with LN, LM and the solid curves give $g_{1}$, $\mathrm{g}_{2}, \mathrm{w}_{1}$ and $\mathrm{w}_{2}$, which are the operating points of these converters when the wind powers are $\mathrm{P}_{\mathrm{WF} 1}$ and $\mathrm{P}_{\mathrm{WF} 2}$, respectively. Their dc currents fulfill the condition $\mathrm{I}_{\mathrm{WF} 1}+\mathrm{I}_{\mathrm{WF} 2}=\mathrm{I}_{\mathrm{GS} 1}+\mathrm{I}_{\mathrm{GS} 2}$

The dashed curve shows the V-I characteristics of WF$\mathrm{VSC}_{1}$ when $\mathrm{P}_{\mathrm{WF} 1}$ is decreased to $\mathrm{P}_{\mathrm{WF} 1}^{\prime}$ due to a reduced wind speed. The dc current decreases since the power is

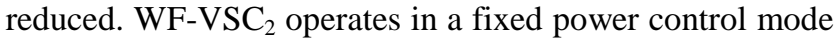
to extract maximum power. The M-HVDC system reaches a new equilibrium state with a new dc voltage level $\mathrm{V}^{\prime}{ }_{\mathrm{WF} 1}=\mathrm{V}^{\prime}{ }_{\mathrm{WF} 2}=\mathrm{V}_{\mathrm{GS} 1}^{\prime}=\mathrm{V}_{\mathrm{GS} 2}$, represented by the dashed line in Fig. 5. Points $\mathrm{w}_{1}{ }^{\prime}, \mathrm{w}_{2}{ }^{\prime}, \mathrm{g}_{1}{ }^{\prime}$ and $\mathrm{g}_{2}{ }^{\prime}$ are intersections of dashed horizontal line, droop lines LN and LM, and the dashed curve that represent the system new operating points. The dc current complies with the equilibrium condition $\mathrm{I}_{\mathrm{WF} 1}^{\prime}+\mathrm{I}_{\mathrm{WF} 2}^{\prime}=\mathrm{I}_{\mathrm{GS} 1}^{\prime}+\mathrm{I}_{\mathrm{GS} 2}^{\prime}$.

The V-I characteristics for the two steady state voltages have been exaggerated for clarity.

Assume the actual dc voltages at each VSC station accurately track their references when using the dc voltage controller. Then the reference dc voltages of GS-VSCs are: $V_{G S 1}=V_{G S 0}+K_{G S 1} I_{G S 1}, V_{G S 2}=V_{G S 0}+K_{G S 2} I_{G S 2}$ In (1), the converter dc voltages differ because of different dc cables impedances. So:

$$
V_{G S 0}+2 R_{G S 1} I_{G S 1}=V_{G S 0}+2 R_{G S 2} I_{G S 2}
$$

where $R_{G S 1}$ and $R_{G S 2}$ are the resistances of the dc cables connected to the GS-VSCs. Thus the shared power between the two grid side converters is given by:

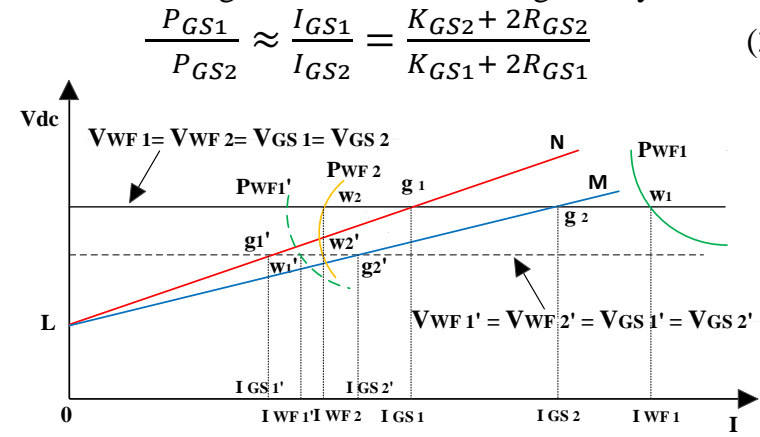

Fig. 5: Operating points and V-I characteristics of configuration-1.

\section{II.2: DC voltage droop control on wind farm side converters}

For the system in Fig. 1, a simultaneous symmetrical ac fault on the onshore ac grids forces the GS-VSCs to move to a current limiting mode. Then the WF-VSCs become responsible for regulating the dc grid voltage by using the decentralized droop control in Fig. 4 with the d-q controller of Fig. 3 in each WF-VSC.

The GS-VSCs deliver the received power to onshore ac grids. Figs. 6 and 7 illustrate, respectively, the control schemes for GS-VSC 1 and GS-VSC 2 . The controller in Fig. 6 regulates the real and imaginary power transfer through GS-VSC 1 with references $\mathrm{P}_{\mathrm{g}}$ * and $\mathrm{Q}_{\mathrm{g}}$ * while GS-VSC $\mathrm{C}_{2}$, 
being connected to a weak ac grid, controls the active power and the ac voltage. The actual dc voltage is used as the reference. Active power transfer is achieved through the real power error $\left(\mathrm{P}_{\mathrm{g}}^{*}-\mathrm{P}_{\mathrm{g}}\right)$ via a PI controller. Compensation term $L \omega \mathrm{i}_{\mathrm{d}}$ is added to decouple d-axis and $\mathrm{q}$-axis control. The d-axis grid voltage $\mathrm{V}_{\mathrm{dg}}$ is also added as feed forward control. This gives the $\mathrm{d}$-axis voltage component $\mathrm{V}_{\mathrm{d}}$. The active power control mode is the same in both control schemes, as depicted in Figs. 6 and 7 [21]. Reactive power control, via the q-axis current controller, is same as in Fig. 3.

In Fig. 7, the q-axis current is controlled to regulate the ac voltage of the connected ac grid. The error $\left(\mathrm{V}_{\mathrm{acg}}^{*}-\mathrm{V}_{\mathrm{acg}}\right)$ is for the ac voltage controller, then $\mathrm{i}_{\mathrm{q}}^{*}$. The $\mathrm{i}_{\mathrm{q}}$ and $\mathrm{i}_{\mathrm{q}}^{*}$ current error is fed to the q-axis current controller. The compensation term $-\mathrm{L} \omega \mathrm{i}_{\mathrm{q}}$ decouples the $\mathrm{d}$-axis and q-axis control, giving the q-axis component $\mathrm{V}_{\mathrm{q}}$.

Converter voltage components $\mathrm{V}_{\mathrm{d}}$ and $\mathrm{V}_{\mathrm{q}}$ are then converted to three phase voltages for PWM control as shown in Figs. 6 and 7. Low pass filters are used for voltage $\mathrm{V}^{\mathrm{dqg}}$ and currents $\mathrm{i}^{\mathrm{dqg}}$ measurements to calculate the voltage and power feedback, in order to damp the fast transients during power change. These low pass filters are tuned ten times faster than the current loop [15].Control parameters are given in Table I.

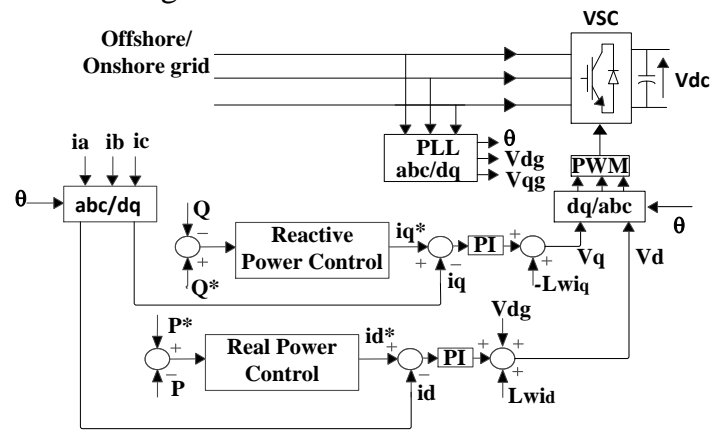

Fig. 6: Active and reactive power control of GS-VSC 1 .

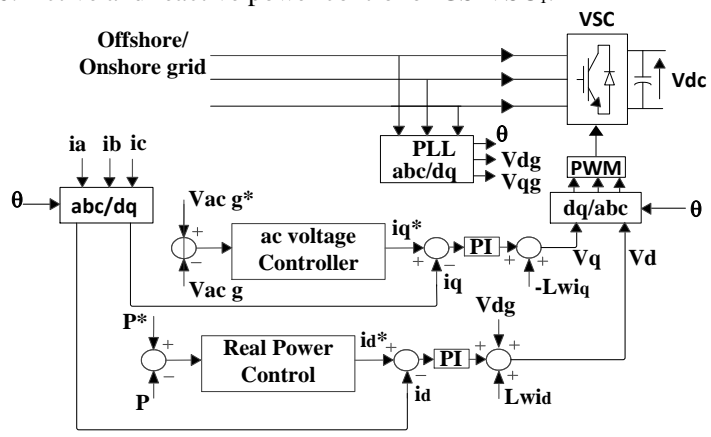

Fig. 7: Active power and ac voltage control of GS-VSC 2 .

\section{II.2.1: V-I characteristics of configuration 2}

The V-I characteristics for the proposed system is shown in Fig. 8. Straight lines $\mathrm{LN}$ and $\mathrm{LM}$ demonstrate the droop characteristics of $\mathrm{WF}^{-\mathrm{VSC}_{1}}$ and $\mathrm{WF}^{-\mathrm{VSC}_{2}}$ based on (1). The solid curves display the characteristics of GS-VSC ${ }_{1}$ and GS-VSC $\mathrm{V}_{2}$. It is assumed the VSCs have same voltages, that is, $\mathrm{V}_{\mathrm{WF} 1}=\mathrm{V}_{\mathrm{WF} 2}=\mathrm{V}_{\mathrm{GS} 1}=\mathrm{V}_{\mathrm{GS} 2}$ and are represented by the solid horizontal line in Fig. 8. Then the intersections of the horizontal line with LN, LM and the solid curves give $\mathrm{w}_{1}$, $\mathrm{w}_{2}, \mathrm{~g}_{1}$ and $\mathrm{g}_{2}$, which are the system operating points, provided wind powers are $\mathrm{P}_{\mathrm{WF} 1}$ and $\mathrm{P}_{\mathrm{WF} 2}$. Converter $\mathrm{dc}$ currents fulfill the condition $\mathrm{I}_{\mathrm{WF} 1}+\mathrm{I}_{\mathrm{WF} 2}=\mathrm{I}_{\mathrm{GS} 1}+\mathrm{I}_{\mathrm{GS} 2}$.

The dashed curves in Fig. 8 represent the V-I characteristics of GS-VSC 1 and $G S-V_{2} C_{2}$ when the utility power demand is reduced. A power demand decrease causes a grid side overvoltage, requiring a dc current decrease. So each WF-VSC moves into a power reduction mode through droop control, to maintain a steady state system. The system reaches a new equilibrium state with voltages $\mathrm{V}^{\prime}{ }_{\mathrm{WF} 1}=\mathrm{V}^{\prime}{ }_{\mathrm{WF} 2}=\mathrm{V}_{\mathrm{GS} 1}^{\prime}=\mathrm{V}_{\mathrm{GS} 2}^{\prime}$ and dc currents $\mathrm{I}_{\mathrm{WF} 1}^{\prime}+\mathrm{I}_{\mathrm{WF} 2}^{\prime}=\mathrm{I}_{\mathrm{GS} 1}^{\prime}+\mathrm{I}_{\mathrm{GS} 2}^{\prime}$. Points $\mathrm{w}_{1}{ }^{\prime}, \mathrm{w}_{2}{ }^{\prime}, \mathrm{g}_{1}{ }^{\prime}$ and $\mathrm{g}_{2}{ }^{\prime}$ at which the dashed horizontal line intersects the straight lines LN, LM and dashed curves, are each converter new operating points. Similarly, system operating points can be found when the wind power increases to $\mathrm{P}^{\prime \prime}{ }_{\text {WF1 }}$ and $\mathrm{P}^{\prime \prime}{ }_{\mathrm{WF} 2}$.

As generated wind energy is injected into the dc grid based on a power transmission ratio:

$$
\frac{P_{W F 1}}{P_{W F 2}} \approx \frac{I_{W F 1}}{I_{W F 2}}=m \text {. }
$$

Then by using (1), (4) becomes:

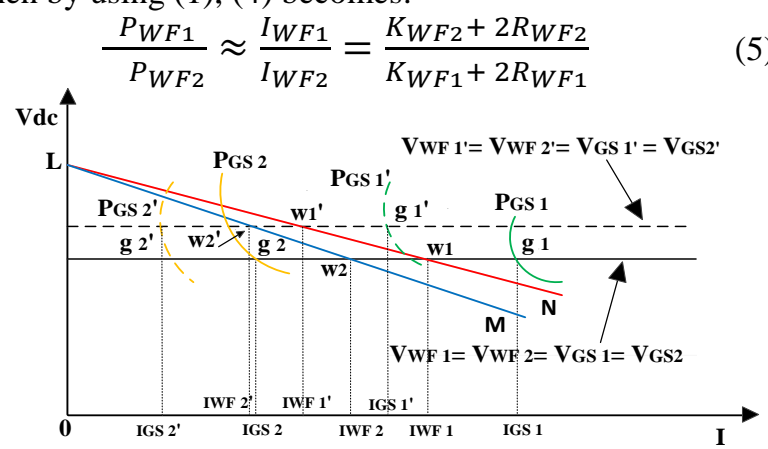

Fig. 8: Operating points and V-I characteristics of configuration -2.

\section{II.3: Generalized droop control strategy}

Despite the popularity of voltage droop control, it has drawbacks. It cannot perform fixed power control for a specific VSC station or fixed dc voltage control, if necessary. In order to overcome this, a generalized droop control strategy performs voltage and power control of $\mathrm{M}$ HVDC grids [6]. This strategy is flexible in terms of dc voltage control and power sharing based on droop characteristics.

A control scheme is implemented through the dual hierarchical structure shown in Fig. 9 and its two operating modes are used as shown in Fig. 10 [6]. This allows the controller to transit schemes softly and abruptly depending on M-HVDC system parameters, as expressed mathematically by:

$$
\alpha V d c+\beta P+\gamma=0 .
$$

The control diagram for this mathematical expression is shown in Fig. 11. The coefficients $\alpha, \beta$ and $\gamma$ in (6) mainly depend on the M-HVDC system conditions (voltage, power ,etc.) and used to select the operating mode for system.

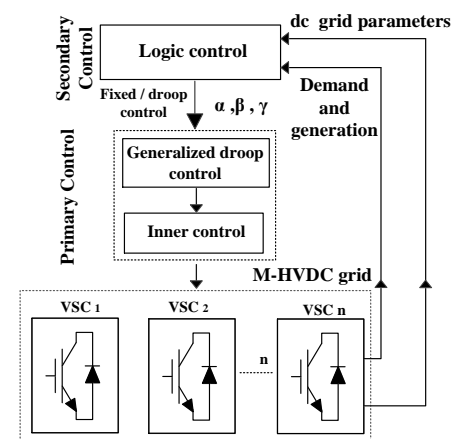

Fig. 9: Dual hierarchical control structure for M-HVDC grid.

The configuration shown in Fig. 12 comprises one offshore wind farm (WF-VSC ${ }_{1}$ ) connected to three onshore grid converters $\left(\mathrm{GS}-\mathrm{VSC}_{1}, \mathrm{GS}-\mathrm{VSC}_{2}\right.$ and $\left.\mathrm{GS}-\mathrm{VSC}_{3}\right)$. The 


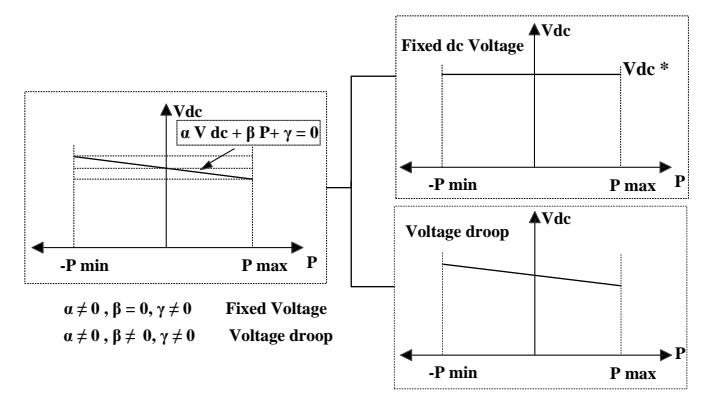

Fig. 10: Generalized droop control characteristics with employed modes.

system transfers power between three mainland ac grids through submarine cables and the wind farm is tapped with a tee connection. It is potentially the first application of a meshed M-HVDC network, and is off the U.K. coast [27]. Two control scenarios are considered.

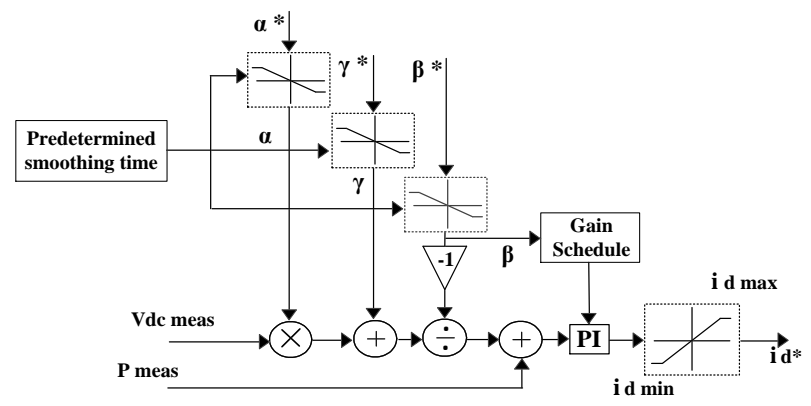

Fig. 11: Implementation of generalized droop control with smooth operating mode change [6].

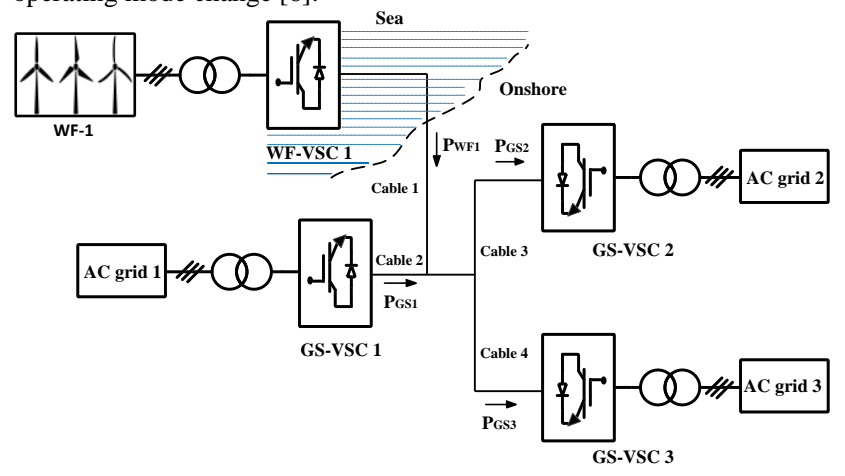

Fig. 12: M-HVDC system with T-connection of offshore wind farm to three onshore ac grids through submarine HVDC cables.

\section{II.3.1: V-I characteristics of configuration 3}

\section{$i$. Scenario 1}

With the V-I characteristics for scenario 1, that is, the fixed dc voltage control approach in Fig. 13, GS-VSC 3 has fixed dc voltage control, represented by the horizontal line,

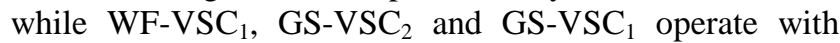
fixed power control $\mathrm{P}_{\mathrm{WF} 1}, \mathrm{P}_{\mathrm{GS} 2}$ and $\mathrm{P}_{\mathrm{GS} 1}$, represented by the solid curves. If all the converters and cables are lossless, the constant $\mathrm{dc}$ voltage across the terminals is $\mathrm{V}_{\mathrm{WF} 1}=\mathrm{V}_{\mathrm{GS} 1}=\mathrm{V}_{\mathrm{GS} 2}=\mathrm{V}_{\mathrm{GS} 3}$, represented by the solid horizontal line in Fig. 13. $w_{1}, g_{1}$ and $g_{2}$ are the operating points of ${\mathrm{WF}-V S C_{1}, \mathrm{GS}-\mathrm{VSC}_{1} \text { and GS-VSC }}_{2}$, respectively, being the intersections of the horizontal line and the solid curves.

The dc current of GS-VSC 3 is $\mathrm{I}_{\mathrm{GS} 3}=\mathrm{I}_{\mathrm{GS} 1}+\mathrm{I}_{\mathrm{GS} 2}+\mathrm{I}_{\mathrm{WF} 1}$ and the operating point of $\mathrm{GSVSC}_{3}$ is $\mathrm{g}_{3}\left(\mathrm{I}_{\mathrm{GS} 3}, \mathrm{~V}_{\mathrm{GS} 3}\right)$. Again the effect on the system dc voltage and operating point can be explained in terms of the dashed curves when the power from $\mathrm{WF}_{1}$ or grid-1 is changed as in Fig. 13.

The V-I characteristics of the fixed dc voltage control mode are changed to Fig. 5 in the event of a permanent failure of the fixed dc voltage control terminal GS-VSC 3 . At this instant, the generalized droop control scheme is used to change the control mode of the remaining two GS-
VSCs to de voltage droop control [6] that follow the V-I characteristics in Fig. 5

\section{ii. Scenario 2}

Scenario 2 is based on conventional droop control and it's V-I characteristics shown in Fig. 14. The solid curves

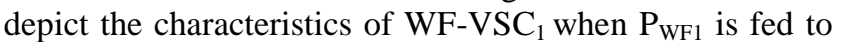
the dc grid and $\mathrm{P}_{\mathrm{GS} 1}$ is the power drawn by GS-VSC 1 . LN and $\mathrm{LM}$ show the droop characteristics of $\mathrm{GS}-\mathrm{VSC}_{2}$ and $\mathrm{GS}_{\mathrm{VSC}}$, determined by (1) and the droop constants are different for each GS-VSC. If the system is lossless, all the $\mathrm{dc}$ voltages are the same $\left(\mathrm{V}_{\mathrm{WF} 1}=\mathrm{V}_{\mathrm{GS} 1}=\mathrm{V}_{\mathrm{GS} 2}=\mathrm{V}_{\mathrm{GS} 3}\right)$, represented by the solid horizontal line. $\mathrm{g}_{1}, \mathrm{~g}_{2}, \mathrm{~g}_{3}$ and $\mathrm{w}_{1}$ are the operating points obtained from intersections with the horizontal line, LN, LM and the solid curves. The dc current satisfies $\mathrm{I}_{\mathrm{WF} 1}=\mathrm{I}_{\mathrm{GS} 1}+\mathrm{I}_{\mathrm{GS} 2}+\mathrm{I}_{\mathrm{GS} 3}$. The effect on the system dc voltage and operating points, again is the dashed curves and horizontal line intersections when power from $\mathrm{WF}_{1}$ or grid-1 changes, as in Fig. 14.

The system V-I characteristics discussed in the second scenario is transformed to Fig. 13 with failure of $\mathrm{GS}-\mathrm{VSC}_{3}$; loss of one coordinated dc voltage droop control terminal. Although the remaining unaccompanied droop controlled converter can control the dc voltage, it may produce massive swings in dc grid voltage during the power change. A control scheme is proposed where the unaccompanied droop control terminal is smoothly transits to fix dc voltage control through the generalized droop control technique, as shown in Fig. 11. Now, GS-VSC ${ }_{1}$ and $\mathrm{GS}_{\mathrm{VSC}}$ are responsible for fixed dc voltage control and fixed active power control, respectively, and follow the V-I characteristics in Fig. 13.

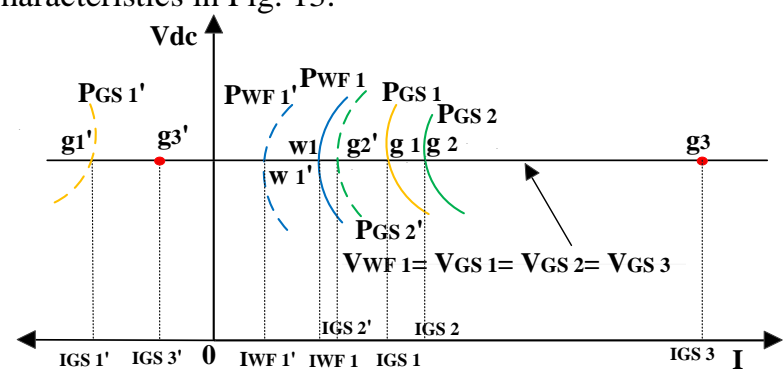

Fig. 13: Operating points and V-I characteristics for fixed dc voltage control configuration-3, sceneraio-1.

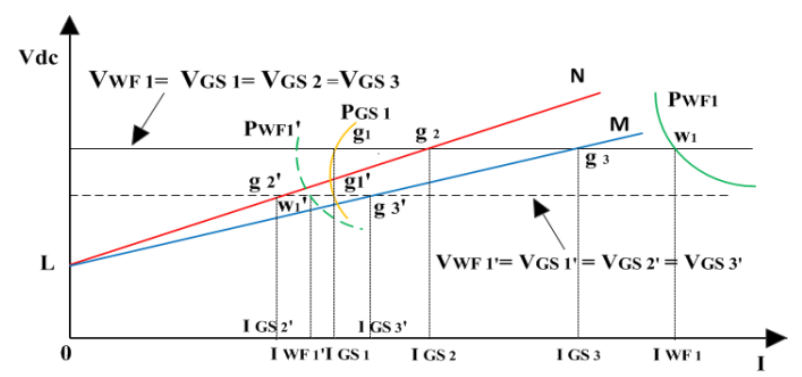

Fig. 14: Operating points and V-I characteristics for dc voltage droop control of configuration-3, scenario- 2 .

\section{ESTABLISHED EXPERIMENTAL WORKBENCH}

An experimental workbench is used to assess the operation and control strategies described in section II, during steady state and dynamic conditions. The platform comprises four VSCs interconnected on their dc sides. Photographs and emulated system configurations are shown in Figs. 15 and 16, respectively. All components are scaled down. 


\section{III.1: Power Converter}

Each VSC power converter is a two level insulated gate bipolar transistor (IGBT) based converter, consisting of three boards: power, driver and control boards. The power board is a module of three IGBT legs, with an additional branch for braking capability, and shown in Fig. 17. TI DSP TMS320F28335 is the core of the control board. The driver board enables the control board to access the power board IGBTs, which provides the necessary gate excitation signals and introduces arm dead time in each leg. The driver board also supports the analog based protection like: over current, over temperature, over voltage, and driver error. Each power converter is connected to an ac grid through a coupling filter. Two ac currents and voltages, dc voltage, and dc current are measured. An ac circuit breaker (CB) connects a power converter to the ac network once it is synchronized. DC circuit breakers allow the VSC connection to the dc grid. The variable nature of the wind is emulated using C coding in a DSP, to obtain the wind power for the control board. Power converter parameters are given in Table II.

A DL850 Yokogawa scope is used to monitor and measure the system input and output parameters. The dc power is calculated by multiplication of the dc voltage and dc current, measured from dc side of each VSC station, using X-viewers software.

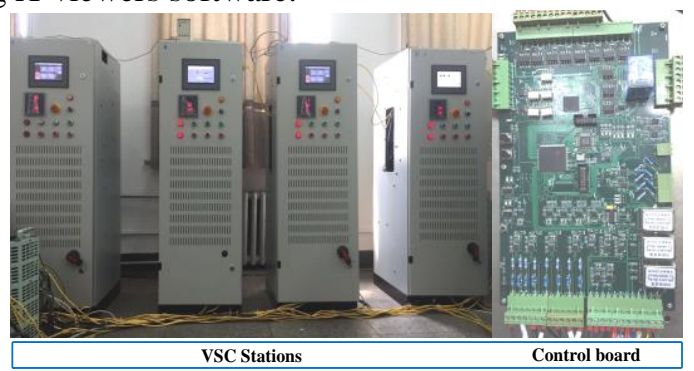

Fig. 15: VSC converters of experimental platform and main driver board of the power converters (right).

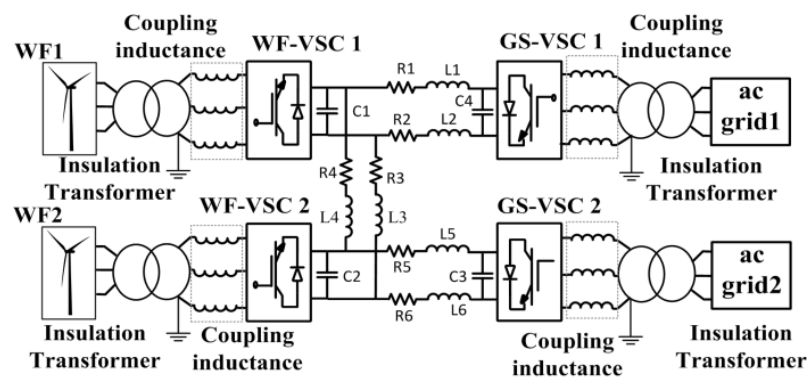

Fig. 16 (a): Experimental platform for configurations 1 and 2 .

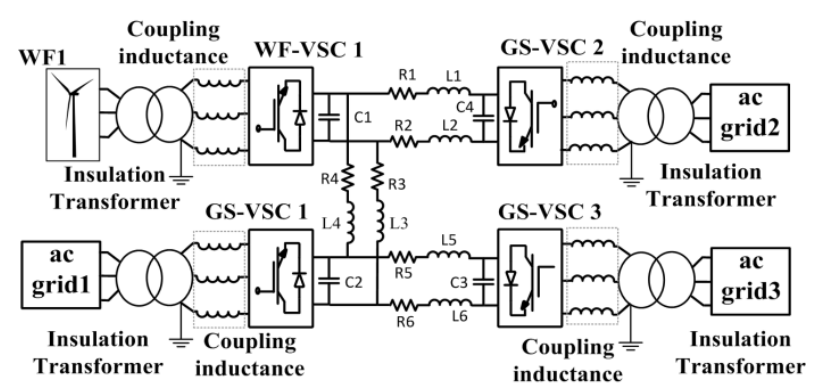

Fig. 16 (b): Experimental platform for configuration-3.

\section{III.2: DC grid}

DC cables are emulated by a $\pi$ equivalent, where the equivalent cable capacitance is integrated into the converter capacitance. Inductance and resistance are added to dc cables as shown in Table III. DC link inductance is added to confine dc faults levels, to enable the dc circuit breakers $(\mathrm{CB})$ to operate [22]. DC faults and system ride through will be investigated in future research with DCCB operating times of $5 \mathrm{~ms}$ [23], [24].

\section{III.3: $M-H V D C$ earthing configuration.}

Various earthing schemes are advocated. Traditionally, earthing of M-HVDC systems takes place at: the dc link capacitor midpoint, ac side transformer and/or each cable end [25]. Currently no formal standard for earthing of MHVDC has been defined [26]. The M-HVDC systems in this paper are grounded at the grid side of the transformer while dc cable ends and dc link remains unearthed is outlined in Fig. 16, since focus is on M-HVDC control techniques rather than earthing configurations. All earthing used within a M-HVDC grid is solid, that is, low impedance [27]. This aspect will be addressed in future research, when assessing dc grid faults.

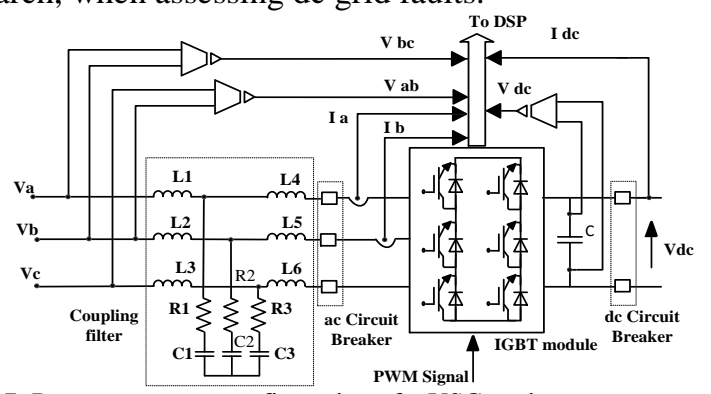

Fig. 17: Power converter configuration of a VSC station.

Table II: Characteristics of power converter.

\begin{tabular}{lc}
\hline \hline \multicolumn{1}{c}{ Parameters } & Values \\
\hline \hline Switching frequency & $10.0 \mathrm{kHz}$ \\
DC grid voltage & $100 \mathrm{~V}$ \\
Max. power of each VSC & $800 \mathrm{~W}$ \\
Coupling inductance & $1.58 \mathrm{mH}$ \\
Converter capacitance & $1400 \mu \mathrm{F}$ \\
DSP & TMS320F28335 \\
Sampling time of DSP & $100 \mu \mathrm{s}$ \\
\hline
\end{tabular}

Table III: Parameters of dc grid.

\begin{tabular}{llc}
\hline \hline DC cable & Resistance & Inductance \\
\hline \hline Cable 1 & $0.10 \mathrm{ohm}$ & $0.5 \mathrm{mH}$ \\
Cable 2 & $0.12 \mathrm{ohm}$ & $1.0 \mathrm{mH}$ \\
Cable 3 & $0.44 \mathrm{ohm}$ & $1.5 \mathrm{mH}$ \\
\hline
\end{tabular}

\section{EXPERIMENTAL RESULTS}

To assess the operation and control strategies, three tests are simulated and experimentally configured, viz., wind power change, permanent disconnection of a VSC, and sudden power change demand from an onshore ac side converter. The base power and dc voltage for normalization are $600 \mathrm{~W}$ and $100 \mathrm{~V}$, respectively.

\section{IV.1: DC voltage droop control on grid side converters}

The M-HVDC of Fig. 1 is assessed with the experimental platform arranged as in Fig. 16 (a), using the control parameters in Table I. The proportional droop control of Fig. 4 is applied to the GS-VSCs while the WFVSCs operate with a fix active power and ac voltage control to extract maximum power.

i. The wind power from $\mathrm{WF}_{1}$ is ramped to $0.6 \mathrm{pu}$ from $0.4 \mathrm{pu}$. Power is transmitted to the mainland ac

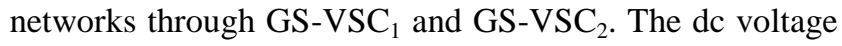
profile and power behavior for test-1 are shown in Fig. 18. 
Power through $\mathrm{WF}_{2}$ remains constant at $0.8 \mathrm{pu}$. The network dc voltage level rises to $1.02 \mathrm{pu}$ through coordinated droop control of the grid side converters as the power transfer increases.

ii. In second case, the load demand of GS-VSC ${ }_{1}$ is increased to $-0.6 \mathrm{pu}$ from $-0.5 \mathrm{pu}$ and in response the power transferred through $\mathrm{GS}-\mathrm{VSC}_{2}$ is reduced to $-0.8 \mathrm{pu}$. A power short-fall appears in dc grid because of the extra power demand of GS-VSC 1 , which causes a reduced dc voltage level of $1.01 \mathrm{pu}$, as shown in second half of Fig. 18 , while the wind powers remained unchanged.

iii. The third test involves the disconnection of GS$\mathrm{VSC}_{1}$. Fig. 19 depicts the dc voltage and active power of the experimental M-HVDC grid. The power in GS-VSC falls to zero from -0.4 pu because of its sudden disconnection due to a symmetric fault on its ac grid side. Power transferred through GS-VSC 2 increases to $-1.2 \mathrm{pu}$ provided by the WF-VSCs, when keeping $\mathrm{V}_{\mathrm{dc}}$ within the permissible range of $\pm 5 \%$. Wind power extraction remains constant.

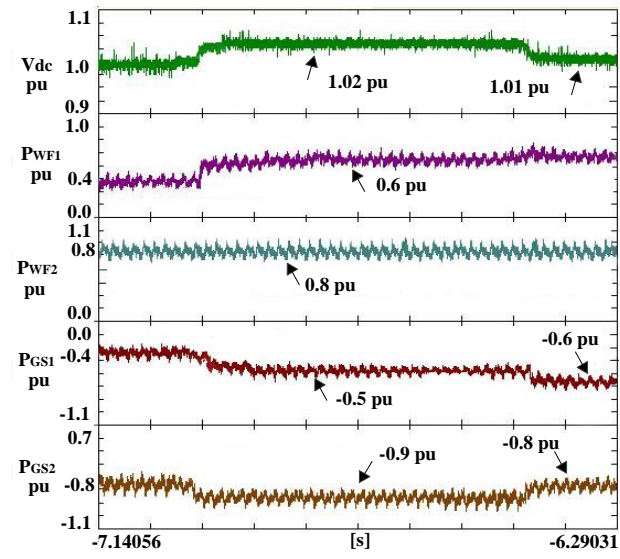

Fig. 18: DC voltage and real power during change in power reference from $\mathrm{WF}_{1}$ and $\mathrm{GS}_{1}$, respectively (Experimental, configuration-1).

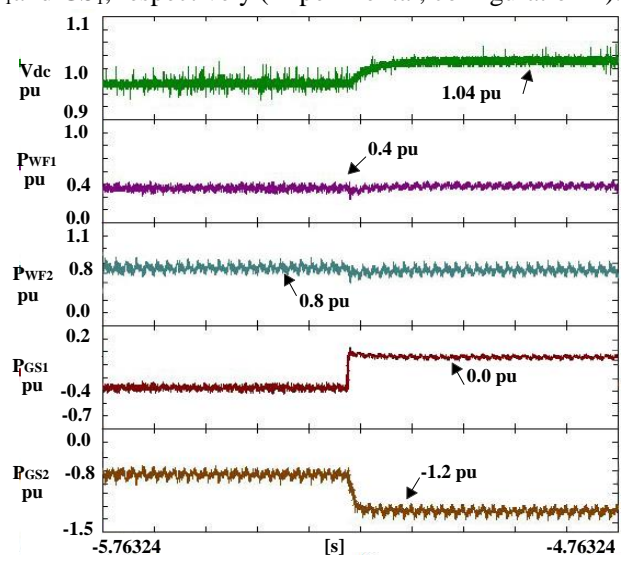

Fig. 19: DC voltage and active power during ultimate disconnection of GS-VSC ${ }_{1}$ (Experimental, configuration-1).

The operation and control of M-HVDC configuration-1 under all three tests show that the designed control is effective. Such control and system architecture can be used when maximum wind power extraction is needed from offshore WFs and the onshore converters are distant from the load centers.

\section{IV.2: DC voltage droop control on wind farm side converters}

The multi-terminal VSC based HVDC system of Fig. 1 is considered when simultaneous voltage sag appears on the mainland ac grids, whence dc voltage control is shifted to the WF-VSCs by adopting droop control as described in section II. The experimental platform is shown in Fig. 16 (a), using the control parameters in Table I.

i. Initially wind power variation is observed. The M-HVDC shifts to a new transmission ratio according to the proposed control methodology to keep the system stable and to transmit the demanded power to the ac grid. Fig. 20 shows the dc grid voltage and power of the experimental M-HVDC network. When $\mathrm{P}_{\mathrm{WF} 1}$ starts to increase, the dc voltage rises to attain a new equilibrium, giving a new transmission ratio, by deploying $\mathrm{WF}_{2}$ in a coordination mode.

The power from $\mathrm{WF}_{1}$ rises to $0.5 \mathrm{pu}$ while $\mathrm{WF}_{2}$ moves to a power reduction mode to achieve equilibrium according to the improved droop control, and the dc voltage rises. The new dc voltage and $\mathrm{P}_{\mathrm{WF} 2}$ levels are $1.02 \mathrm{pu}$ and $0.7 \mathrm{pu}$, as shown in Fig. 20. Power transfer through the grid side converters remains constant at $\mathrm{P}_{\mathrm{GS} 1}=-0.4 \mathrm{pu}$ and $\mathrm{P}_{\mathrm{GS} 2}=-0.8$ pu, respectively.

ii. The second case is for a power demand change from the onshore ac grids, as seen in the second half period of Fig. 20. The load demand from GS-VSC 1 is increased to $-0.6 \mathrm{pu}$, and the dc voltage level falls to $0.99 \mathrm{pu}$ when providing the necessary energy. In this scenario, the WFVSCs moved to a power surge mode through proportional droop control to stabilize the system voltage.

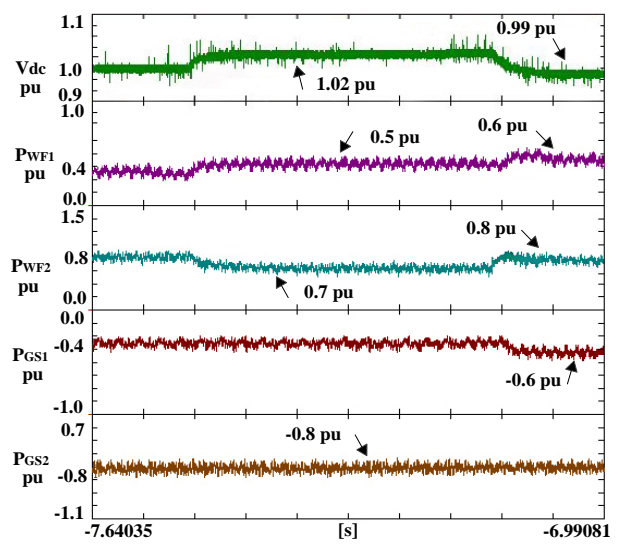

Fig. 20: DC voltage and active power during change in power reference from WF-VSC ${ }_{1}$ and GS-VSC ${ }_{1}$ (Experimental, configuration-2).

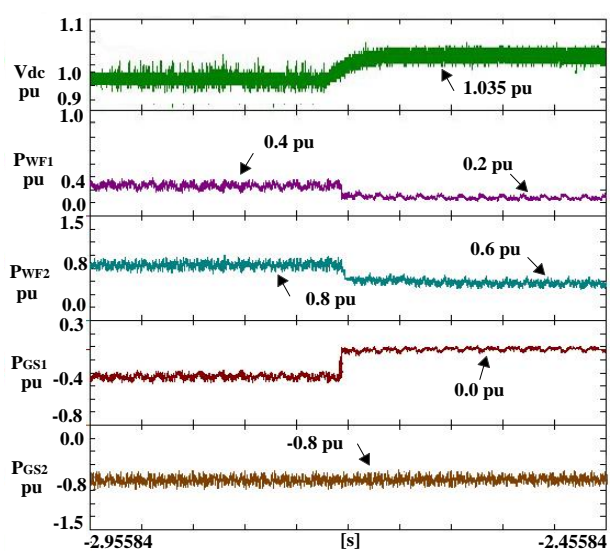

Fig. 21: DC voltage and active power during ultimate disconnection of $\mathrm{GS} \mathrm{VSC}_{1}$ (Experimental, configuration-2).

iii. The third test is sudden disconnection of one onshore converter from the M-HVDC network, enabling the observation of the wind farm power reduction scheme using the power transfer ratio, which is inversely proportional to dc voltage.

A symmetrical fault persists on ac grid-1 which leads to permanent disconnection of $\mathrm{GS}-\mathrm{VSC}_{1}$, causing excess system power. The dc voltage rises to $1.035 \mathrm{pu}$ and to keep 
the system voltage within limits, the wind powers $\mathrm{P}_{\mathrm{WF} 1}$ and $\mathrm{P}_{\mathrm{WF} 2}$ are reduced to $0.2 \mathrm{pu}$ and $0.6 \mathrm{pu}$, respectively, after admissible fluctuation. Experimental converter station voltage and power profiles are shown in Fig. 21. Power extraction at the moment of disconnection through the disconnected terminal is zero.

The M-HVDC configuration voltage and power sharing remain within predefined limits during the three tests on the second configuration. Such control and system configuration may find application in M-HVDC systems connected to weak onshore ac grids or main land ac grids which are likely to suffer severe ac faults.

\section{IV.3: Generalized droop control strategy}

\section{IV3.1: Scenario 1}

The system in Fig. 9 is investigated in configuration3 , during control scenario 1 . That is fixed power control, when power from the T-connected offshore wind farm and

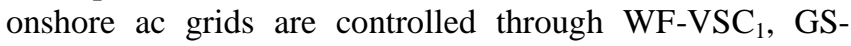

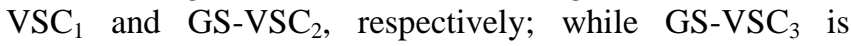
responsible for fixed level $\mathrm{dc}$ voltage control. The experimental setup is connected as in Fig. 16 (b). Initially, $0.3 \mathrm{pu}$ wind power is transmitted from $\mathrm{WF}_{1}$ to the dc grid and power from the onshore ac grid- 1 is regulated at $0.4 \mathrm{pu}$. Thus, the total power transported through GS-VSC 3 and GS$\mathrm{VSC}_{2}$ to ac grids 2 and 3 is -0.7 pu, as shown in Fig. 22.

i. $\quad$ The wind power is ramped from 0.3 pu to $0.6 \mathrm{pu}$ and the power transferred to ac grids 2 and 3 accumulate to -1.0 pu from $-0.7 \mathrm{pu}$. The dc voltage is controlled to $1.0 \mathrm{pu}$, as shown in Fig. 22, and during the power transition, the dc voltage level remains within the prescribed limits of $\pm 5 \%$.

ii. The second test assesses power variation from ac grid-1. The load demand from GS-VSC $_{1}$ reduces to $-0.2 \mathrm{pu}$. The power through all VSCs except GS-VSC 3 remains near constant but the dc voltage drops, as shown in second half period of Fig. 22, by adjusting the power transfer though $\mathrm{GS}-\mathrm{VSC}_{3}$.

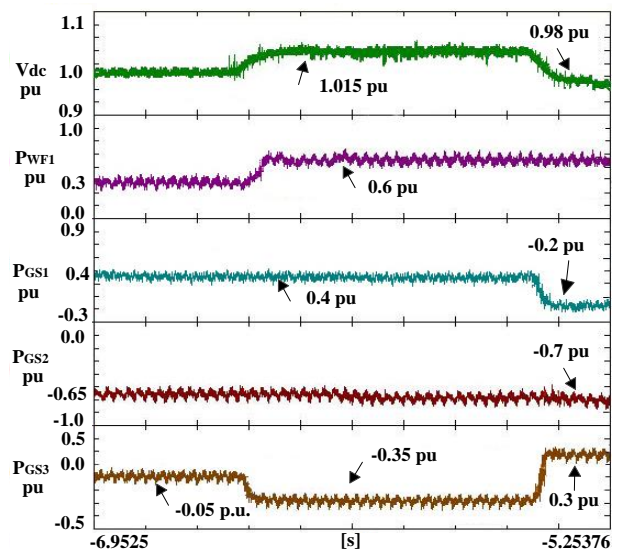

Fig. 22: DC voltage and active power during change in power reference from $\mathrm{WF}_{1}$ and $\mathrm{GS}_{1}$, respectively (Experimental, configuration-3, Scenario$1)$.

iii. Third case analyzed corresponds to disconnection of the dc voltage controlled terminal at GS-VSC 3 . At the moment of disconnection, dc voltage control responsibility is transferred through generalized droop control to $\mathrm{GS}_{-} \mathrm{VSC}_{2}$ and GS-VSC ${ }_{1}$. Then power transfer balance and dc voltage stability in the M-HVDC network is achieved as shown in Fig. 23. The dc voltage reduces to $0.98 \mathrm{pu}$ during control transfer.

System oscillations are controlled with the proposed control scheme along with properly tuned PI control parameters since the M-HVDC system safely shifts its equilibrium state after disconnection of the fixed dc voltage control terminal, that is, the master terminal. The generalized droop control scheme overcomes the error in a master slave approach and is a candidate for meshed grids.

\section{IV3.2: Scenario 2}

The second scenario of configuration- 3 considers the MHVDC configuration shown in Fig. 9. The wind power from

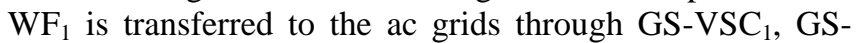
$\mathrm{VSC}_{2}$ and $\mathrm{GS}-\mathrm{VSC}_{3}$. GS-VSC 2 and GS-VSC 3 converters share power through droop control to regulate the $\mathrm{dc}$

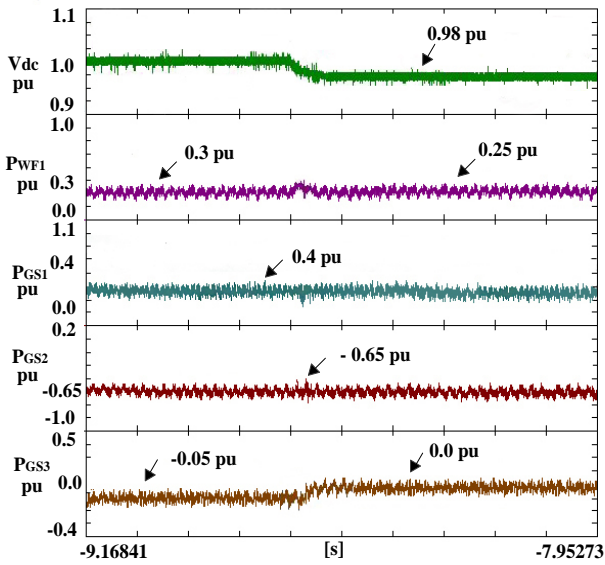

Fig. 23: DC voltage and active power during ultimate disconnection of GS$\mathrm{VSC}_{3}$ (Experimental, configuration-3, scenario-1).

voltage. GS-VSC 1 moves to a fix power control mode for the connected ac grid-1. Experimental workbench is connected as in Fig. 16 (b).

i. The wind power increases from $0.6 \mathrm{pu}$ to $0.8 \mathrm{pu}$,

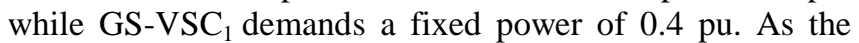
power transferred increases, the HVDC grid dc voltage increases to $1.02 \mathrm{pu}$ and the power transmitted to ac grids 2 and 3 increases to $-0.5 \mathrm{pu}$ and $-0.7 \mathrm{pu}$, respectively, as per the droop control, to a new stable operating point. The power transfer and dc voltage behavior are shown in Fig. 24.

ii. Change in power demand from GS-VSC 2 is observed in the second test as shown in Fig. 24. Load demand through GS-VSC 2 is increased to $-0.6 \mathrm{pu}$ due to the extra power demand from ac grid-2; a short-fall of power appears in the dc grid. Droop control plays its role to achieve an equilibrium condition by reducing the $\mathrm{dc}$ grid voltage to $0.99 \mathrm{pu}$ and $\mathrm{P}_{\mathrm{GS} 3}$ to $-0.6 \mathrm{pu}$, as seen in the second half period of Fig. 24. Power through WF-VSC $\mathrm{V}_{1}$ and GS-VSC ${ }_{1}$ remains near unchanged.

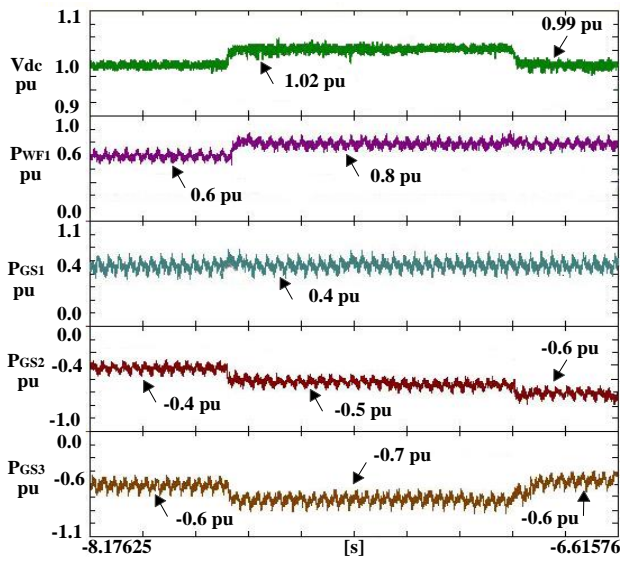

Fig. 24: DC voltage and active power during change in power reference from $\mathrm{WF}_{1}$ and $\mathrm{GS}_{2}$, respectively (Experimental, configuration-3, scenario2). 
iii. The last test applied to the final configuration is GS$\mathrm{VSC}_{2}$ disconnection due to a severe fault on ac grid-2, as shown in Fig. 25. The droop control of GS-VSC 3 moves to fix dc voltage control through the soft and abrupt generalized droop control structure. In Fig. 25 the dc voltage and power flow are not stable without an accompanied droop terminal, so control shifts to fixed dc voltage control, through the generalized droop control structure. GS-VSC 3 and GS-VSC $\mathrm{C}_{1}$ are then responsible for fix dc voltage control and power balance, respectively.

Such a control scheme, configuration-3, scenario 2, finds application when the M-HVDC system is operated with an unaccompanied dc voltage droop control converter. This scheme gives stable dc grid voltage and power flow without any telecommunication, swiftly and smoothly as the results illustrate.

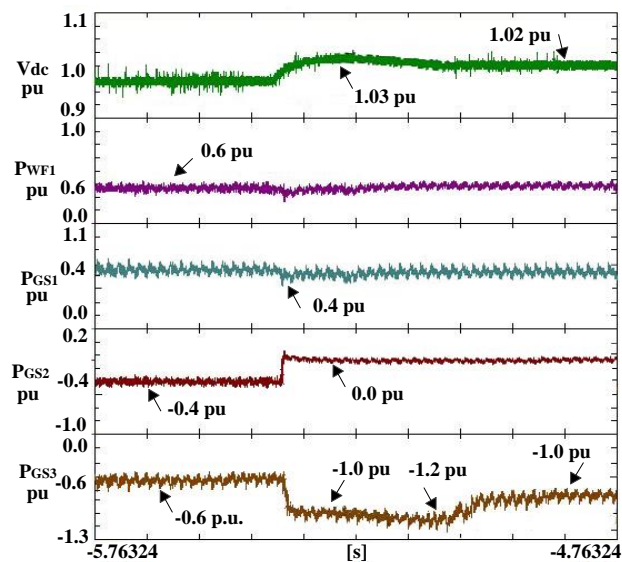

Fig. 25: DC voltage and active power during ultimate disconnection of GS-VSC 2 (Experimental, configuration-3, scenario-2).

\section{CONCLUSION}

Control strategies have been designed for multi terminal VSC HVDC converters. DC grid voltage control, ac wind farm voltage regulation, and active power control to onshore ac grids were the main objectives. Smooth transition between the developed control modes and improved proportional droop control has been achieved.

Three multi-terminal VSC HVDC configurations were considered along with four different control modes. The VI characteristics for all four scenarios were studied and MHVDC system operating points under stable and dynamic conditions were discussed. Configurations 1 and 2 characterized wind energy transmission from multiple offshore points to multiple onshore points of inland ac grids. Configuration 3 characterizes the $\mathrm{T}$ connection of offshore wind farms to a HVDC grid.

A four terminal VSC based HVDC scaled down experimental platform was used to assess the stable operation and control flexibility of M-HVDC configurations. PSCAD/EMTDC was used to analyze the operation and control of configurations. Several experimental case studies were conducted, including wind power variation, loss of a grid-side VSC, and abrupt change in load side demand. The results showed good system performance, all in accordance with the control scheme specifications. Active power and dc grid voltage do not show uncontrolled oscillations during control mode switching through the dual hierarchical control structure, by suitable adjustment of control coefficients.

\section{REFERENCES}

[1] T. Ackermann, "Transmission systems for offshore wind farms," IEEE Power Eng. Rev., vol. 22, no. 12, pp. 23-27, Dec. 2002.

[2] E. Prieto-Araujo, F. D. Bianchi, A. Junyent-Ferre, and O. GomisBellmunt,"Methodology for droop control dynamic analysis of multiterminal VSC-HVDC grids for offshore wind farms," IEEE Trans. Power Del., vol. 26, no. 4, pp. 2476-2485, Oct. 2011.

[3] L. Jiao, G. Joos, C. Abbey, Z. Fengquan, and B. T. Ooi, "Multiterminal DC (MTDC) system for wind farms powered by doublyfed induction generators (DFIGs)," in Proc. 35th Annu. IEEE PESC, Jun. 2004,pp. 1413-1418.

[4] N. R. Chaudhuri, R. Majumder, B. Chaudhuri, J. Pan, and R. Nuqui, "Modeling and stability analysis of MTDC grids for offshore wind farms: A case study on the North Sea benchmark system," in Proc. IEEE Power Energy Soc. Gen. Meet., San Diego, CA, USA, Jul. 2011, pp. 1-7.

[5] L. Livermore, J. Liang, and J. Ekanayake, "MTDC VSC technology and its applications for wind power," in Proc. 45th Int. UPEC, Cardiff, U.K., Aug./Sep. 2010, pp. 1-6.

[6] A. Rouzbehi, A. Miranian, J.I. Candela, A. Luna, P. Rodriguez, "A Generalized Voltage Droop Strategy for Control of Multiterminal DC Grids," IEEE Trans. Ind. Appl., vol.51, no.1, pp.607,618, Jan.Feb. 2015.

[7] L. Xu and L. Yao, "DC voltage control and power dispatch of a multiterminal HVDC system for integrating large offshore wind farms," IET Renew. Power Gen., vol. 5, no. 3, pp. 223-233, 2011.

[8] L. Tang and B. T. Ooi, "Locating and isolating DC faults in multiterminal DC systems," IEEE Trans. Power Del., vol. 22, no. 3, pp. 1877-1884, Jul. 2007.

[9] J. Yang, J. E. Fletcher, J. O'Reilly, G. P. Adam, and S. Fan, "Protection scheme design for meshed VSC-HVDC transmission systems of large scale wind farms," in Proc. 9th IET Int. Conf. ACDC Power Transmission., Oct. 2010, pp. 1-5.

[10] J. Liang, O. G. Bellmunt, J. Ekanayake, and N. Jenkins, "Control of multiterminal VSC-HVDC transmission for offshore wind power," in Proc. 13th EPE Appl., Sep. 2009, pp. 1-10.

[11] J. Beerten, D. V. Hertem, and R. Belmans, "VSC MTDC systems with a distributed DC voltage control-A power flow approach," in Proc. IEEE Trondheim PowerTech, Jun. 2011, pp. 1-6.

[12] M. Han, L. Xiong, and L. Wan, "Power-synchronization loop for vector current control of VSC-HVDC connected to weak system," in Proc. IEEE POWERCON, Oct./Nov. 2012, pp. 1-5.

[13] J. Yang, J. E. Fletcher, and J. O'Reilly, "Short-circuit and ground fault analyses and location in VSC-based DC network cables," IEEE Trans. Ind. Electron. vol. 59, no. 10, pp. 3827-3837, Oct. 2012.

[14] PSCAD® Version 4.2, Wind turbine application technical paper, MANITOBA HVDC Research Centre Inc., CEDRAT,2006.

[15] E. Prieto-Araujo, A. Egea-Alvarez, S. Fekri, O. Gomis-Bellmunt, "DC voltage droop control design for multi-terminal HVDC systems considering AC and DC grid dynamics," IEEE Trans. Power Del, vol.PP, no.99, pp.1-1.

[16] D. Jovcic, L. Lamont, K. Abbott, "Control system design for VSC transmission”, Elect. Power Syst. Res., vol. 77, pp. 721 -729, Aug. 2006.

[17] J. Beerten, S. Cole, R. Belmans,"Modeling of Multi-Terminal VSC HVDC Systems with Distributed DC Voltage Control,"IEEE Trans. Power Syst., vol.29, no.1, pp.34-42, Jan. 2014.

[18] J. Blau, "Europe plans a North Sea grid," IEEE Spectr., vol. 47, no. 3, pp. 12-13, Mar. 2010.

[19] R. T. Pinto, S. F. Rodrigues, P. Bauer, and J. Pierik, "Comparison of direct voltage control methods of multi-terminal DC (MTDC) networks through modular dynamic models," in Proc. 14th EPE Appl., Aug./Sep. 2011, pp. 1-10

[20] P. Rault, F. Colas, X. Guillaud, and S. Nguefeu, "Method for small signal stability analysis of VSC-MTDC grids," in Proc. IEEE Power Energy Soc. Gen. Meet., San Diego, CA, USA, Jul. 2012, pp. 1-7.

[21] J. Liang, T. Jing, O. G. Bellmunt, J. Ekanayake, and N. Jenkins, "Operation and control of multiterminal HVDC transmission for offshore wind farms," IEEE Trans. Power Del., vol. 26, pp. 25962604, Oct. 2011.

[22] G. Adam, R. Li, D. Holliday, S. Finney, L. Xu, B. Williams, et al., "Continued Operation of Multi-Terminal HVDC Networks Based on Modular Multilevel Converters," CIGRE, pp. 1-8, 2015

[23] K. Tahata, S. Ka, S. Tokoyoda, K. Kamei, K. Kikuchi, D. Yoshida, et al., "HVDC circuit breakers for HVDC grid applications," in Proc. Cigré AORC Technical Meeting, Tokyo, Japan, 2014 
[24] T. Eriksson, M. Backman, and S. Halen, "A low loss mechanical HVDC breaker for HVDC Grid applications," Proc. Cigré Session, Paris, France, 2014

[25] J. Ying, J. Fletcher, J. O'Reilly, "Short-Circuit and Ground Fault Analyses and Location in VS-based DC Network cables" IEEE Trans. Ind. Electron., vol. 59, no. 10, pp 3827-3837, Oct. 2012.

[26] D.Van Hertem, M. Ghandhari; "Multi-Terminal VSC for European Supergrid: Obstacles" Renewable and Sustainable Energy Reviews, vol. 14 , no. 9 , pp. 3156 - 3163, July 2010.

[27] J. Rafferty, D.J. Morrow, L. Xu, "Analysis of VSC-based HVDC system under DC faults," in Industrial Electronics Society, IECON 2013 - 39th Annual Conf. of the IEEE, vol., no., pp.459-464, 10-13 Nov. 2013.

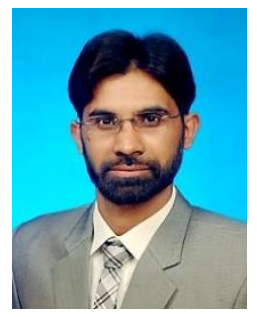

Ali Raza received the B.S. and M.Sc. degrees in electrical engineering from the University of Engineering and Technology, Lahore, Pakistan, in 2010 and 2013, respectively; while currently he is Ph.D. scholar at Harbin Institute of Technology, Harbin, China. His research interests include operation and control of M-VSC-HVDC including its effects on power systems, power system analysis and topological evaluation of M-VSC-HVDC transmission systems for large offshore wind power plants.

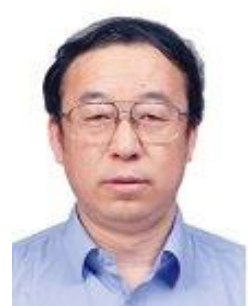

Xu Dianguo (M'97, SM'12) received the B.S. degree in Control Engineering from Harbin Engineering University, Harbin, China, in 1982, and the M.S. and Ph.D. degrees in Electrical Engineering from Harbin Institute of Technology (HIT), Harbin, China, in 1984 and 1989 respectively. In 1984, he joined the Department of Electrical Engineering, HIT as an assistant professor. Since 1994, he has been a professor in the Department of Electrical Engineering, HIT. He was the Dean of School of Electrical Engineering and Automation, HIT from 2000 to 2010. Prof. Xu has authored and coauthored 4 books and published over 600 technical papers. He holds 54 China patents. He was assistant president of the HIT, from 2010 to 2014, while currently he is vice president of HIT. His research interests include renewable energy generation technology, M-VSC-HVDC transmission systems, power quality mitigation, and speed sensorless vector controlled motor drives. Prof. $\mathrm{Xu}$ is a senior member of IEEE, an Associate Editor for the IEEE Transactions on Industrial Electronics. He serves as Chairman of IEEE Harbin Section

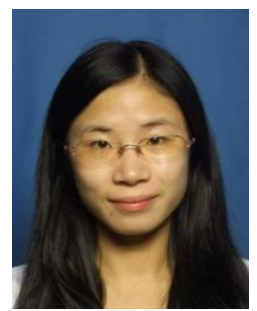

Yuchao Liu received the B.S. degree in electronic information engineering from Harbin University of Science and Technology, China, in 2011 and the M.S. degree in electrical engineering from Harbin Institute of Technology, China, in 2014. Currently, she is pursuing her Ph.D. degree in electrical engineering in Harbin Institute of Technology, China. Her area of interest is the control strategy and protection of multi-terminal dc transmission systems.

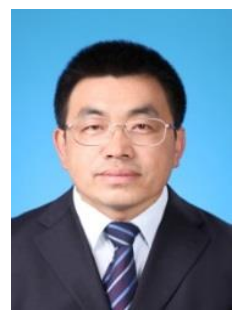

Su Xunwen received Ph.D. degree from North China Electric power University in electrical engineering, China, in 2010. And he completed his post doctorate research from Harbin Institute of Technology, China, in 2014. He is currently working as an associate professor in department of electrical engineering, Heilongjiang University of Science and Technology, China. His research interests include modeling of wind farms, M-VSC-HVDC and renewable energy generation.

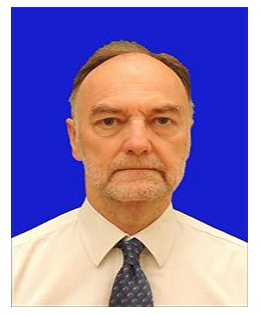

B.W. Williams received the M.Eng.Sc. degree from the University of Adelaide, Australia, in 1978, and the Ph.D. degree from Cambridge University, Cambridge, U.K., in 1980. After seven years as a Lecturer at Imperial College, University of London, U.K., he was appointed to a Chair of Electrical Engineering at Heriot-Watt University, Edinburgh, U.K, in 1986. He is currently a Professor at Strathclyde University, UK. His teaching covers power electronics (in which he has a free internet text) and drive systems. His research activities include power semiconductor modeling and protection, converter topologies, soft switching techniques, and application of ASICs, DSPs and microcontrollers to industrial electronics.

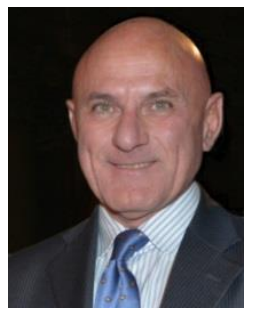

Carlo Cecati (M'92-SM'03-F'06) received the Dr.Ing. degree in electrotechnical engineering from the University of L'Aquila, L'Aquila, Italy, in 1983. Since then, he has been with the University of L'Aquila, L'Aquila, Italy, where since 2006 he has been a Full Professor. Since 2015, he has been with Harbin Institute of Technology, Harbin, China as a 1000 Talent High level foreign expert. In 2007, he was a cofounder of DigiPower Ltd. and he is currently the Technical Director. His research and technical interests include several aspects of power electronics, electrical drives, digital control, distributed generation, and smart grids. From 2013 to 2015 he has been the Editor-in-Chief of the IEEE TRANSACTIONS ON INDUSTRIAL ELECTRONICS. 